\title{
Selection responses for egg production of Fayoumi and Rhode Island Red breeds
}

\author{
M. E. Haque ${ }^{1 *}$, G. K. Deb ${ }^{1}$, M. N. Hasan ${ }^{1}$ and M. H. Ali $^{2}$ \\ ${ }^{1}$ Bangladesh Livestock Research Institute, Savar, Dhaka, ${ }^{2}$ Govt. Poultry Farm, Savar, Dhaka
}

\begin{abstract}
This experiment estimated the selection responses for egg production of Fayoumi (Fay) and Rhode Island Red (RIR) breeds. A total of 3000; belonging Fay 2000 \& RIR 1000 day old chicks were collected from Egypt and Bangladesh Livestock Research Institute (BLRI), Savar, Dhaka respectively, considered as foundation stock. The chicks were brooded for 5 weeks and reared up to 14 weeks of age providing standard feeding and management. After brooding, 640 Fay and 504 RIR pullets were reared in 40 and 36 individual pens respectively, considering as a family. Finally, 30 and 24 best families of Fay and RIR respectively were selected with 420 Fay and 288 RIR pullets at 15 weeks of age, on the basis of age at $1^{\text {st }}$ egg lay, egg production and fertility. Salmonella and mycoplasma free eggs were collected on the basis of blood test (agglutinate test) from the selected families of both the breeds and hatched out for next generation. The experiment was continued up to 40 weeks of age for each generation. The study revealed that hen day egg production of Fay and RIR was higher in Foundation stock (64.39\% in Fay and 68.54\% in RIR) than that of $\mathrm{F}_{1}$ generation (58.6\% in Fay and 46.8\% in RIR) but no significant difference (P > $0.05)$ was observed for livability between Foundation stock and $F_{1}$ generation. Reasons for lower productivity in $F_{1}$ generation may be the poor management practices during growing period. In $F_{2}$ generation, egg production was higher in both the breeds (64.09\% in Fay and $62.05 \%$ in RIR) than in $\mathrm{F}_{1}$ generation. Egg production of RIR was not recorded for $\mathrm{F}_{3}$ generation, as their ability to adopt under farmers condition was very poor. However, in $\mathrm{F}_{3}$ generation, egg production of Fay was higher $(65.82 \%)$ than in $\mathrm{F}_{2}$ generation. Genetic gain in Fay was $0.06 \%, 0.11 \%$ and $0.12 \%$ for $\mathrm{F}_{1}, \mathrm{~F}_{2}$ and $\mathrm{F}_{3}$ generation, respectively. In case of RIR genetic gain was $0.07 \%$ in $\mathrm{F}_{1}$ and $0.18 \%$ in $\mathrm{F}_{2}$ generation. Due to selection slight genetic gain for egg production was obtained in Fay and RIR but further research with larger stock is needed for better understanding of selection responses of these breeds.
\end{abstract}

Key words: Selection, genetic gain, egg production, Fay and RIR

\section{Introduction}

Native chickens, scavenge on cereal by-products and wastes and pieces of biota of rural areas (Rao, 1990) are still playing a significant role on quantitative production of chicken eggs and meat in the developing countries. Increasing consumer demands for organic produces, higher market prices are reflecting their economic importance to farmers. About 98 per cent of farm households keep a few pullets, as a means to earn additional cash and to meet emergency family needs (Huque, et al. 1990). Non-descript native colored chickens, as an important source of meat and eggs are more acceptable to all classes of people (Barua and Howlider, 1990). They produce about 75 per cent of total eggs and 78 per cent of meat consumed domestically (Huque, 1993). Native chickens are early maturing with higher egg fertility than that of exotic breeds (Islam, et al. 1981). Their eggs are tinted having higher threonine and valine content than those of exotic breeds (Khan, 1983). Horst and Mathur (1989) opined that the native fowl still has a position in genetic improvement of tropically orientated stock.

The exotic breeds so far introduced in Bangladesh were not well adapted to scavenging system because of chickens are slow growing and lower egg producers (Barua and Howlider, 1990). They produce only 35

"Corresponding author: ebadull1@yahoo.com Bangladesh Livestock Research Institute, Savar, Dhaka-1341 
-45 eggs per year per hen (Bulbul, 1983; Ahmed and Islam, 1985; Sazzad, 1896 and Huque, et al. 1990). Their mature body weight was 1.0-1.2kg (Panda, 1989; Okada, et al. 1989 and Barua and Howlider, 1990), which, do not encourage rural farmers to extend their poultry operations at commercial level. In that circumstance, crossing of local stock with exotic breeds may yield crossbred that might increase egg production, egg size and body weight.

Among exotic breeds/strains of chicken, farmers are interested to rear Fay and RIR under semi scavenging system of rearing for enhancing rural poultry production. Fay is extensively used in rural areas and well adapted under farm condition in Bangladesh (Anisuzzaman, 1988). This breed is originated from Egypt and possesses the characteristics of early sexual maturity, more egg production and low mortality (Barua, et al. 1998). Some research reports supported that crossing of Fay with exotic breed increased egg production, egg size and body weight. Ali (1989) also found that crossing of Fay with other standard exotic breed improved egg size, growth rate and adaptability of crossbreds under farm condition of Bangladesh.

The Department of Livestock Services (DLS) of Bangladesh has introduced Sonali crossbred chicken (by crossing RIR males with Fay females) in the rural area to improve rural poultry production. The appearances of Sonali chicken are very close to the non-descript native colored chicken. They are very much suited to the semi intensive rearing system in rural areas. They have better production records (50$60 \%$ hen day egg production with feed conversion ratio of 4.33 and lower age of first egg production with 50\% egg production at 179 days) and higher disease resistance (Huque, et al. 1999 and Miah, et al. 2002). The Sonali have the highest egg production, lowest mortality and highest profit per hen among eight crossbred chickens tested under rural condition of Bangladesh (Rahman, et al. 1997). The parents' genetic merits along with proper environment and genotype environment interaction determine production potential and survivability of crossbred pullets. Therefore, increasing productivity of parents through selective breeding might increase productivity of their crossbreds. Considering the above facts, the present experiment aimed to evaluate the possibility of increasing egg production performances of Fay and RIR through selective breeding.

\section{Materials and Methods}

\section{Location and Management}

The study was conducted at Govt. Poultry Farm, Savar, Dhaka, to estimate the selection response of Fayoumi and RIR for egg production performances. A total of 3000; 2000 day old chicks of purebreed Fay from Egypt and 1000 RIR from Bangladesh Livestock Research Institute (BLRI) were collected and reared as foundation stock to produce chicks for next generations. The chicks were brooded (5 weeks) and subsequently reared up to 14 weeks of age providing standard feeding and management. A depth of $15 \mathrm{~cm}$ rice husk was used as litter materials. The photoperiod for brooding period started at 24 hours/day and 
reduced @ 1 hour/week. Initially, 640 Fay pullets were transferred to 40 pens having 16 pullets in each pen (family) and 504 RIR to 36 pens having 14 pullets in each pen at the age of 15 weeks. Finally, 14 and 12 pullets of Fay and RIR from each pen respectively were selected. Male and female ratio was maintained as 1:14 and 1: 12 for Fay and RIR, respectively. There were 30 best families of Fay with 420 pullets and 24 best families RIR with 288 pullets were selected on the basis of age at $1^{\text {st }}$ egg laid, higher egg production and fertility. In each generation, $65.62 \%$ and $57.14 \%$ pullets of Fay and RIR were selected, respectively. The experiment was continued for successive 3 generations for Fay and 2 generations for RIR. The egg production performance was studied for all families (40 for Fay and 36 for RIR) but eggs of the selected families (30 for Fay and 24 for RIR) were collected and hatched for next generation. As per blood test (agglutination test) of the selected families salmonella and mycoplasma free eggs were collected and hatched out. The birds were fed with a ready-made pellet diet containing required amount of $\mathrm{CP}(\%), \mathrm{ME}(\mathrm{Kcal} / \mathrm{Kg})$ and other nutrients. Vaccination (except salmonella), deworming and debeaking schedule was maintained during investigation. Blood test was performed at Poultry Diagnosis Laboratory of Poultry Production Research Division, Bangladesh Livestock Research Institute, Savar, Dhaka. Egg production (up to 40 weeks of age), fertility and livability of Fay and RIR were recorded. Fay, considered to be the best female line, was selected on the basis of age at $1^{\text {st }}$ egg and egg production performance and RIR considered as male line was selected considering the rate of fertility. Eggs from individual pen (family) of foundation stock were collected and hatched for next generation. In case of Fay, hen day egg production (up to 40 weeks of age), fertility, hatchability and livability were recorded up to $\mathrm{F}_{3}$ generation and in case of RIR data were recorded up to $\mathrm{F}_{2}$ generation. Data of RIR were not recorded up to $\mathrm{F}_{3}$ generation, as the performance of RIR pullets was not satisfactory due to inability of RIR breed to adopt in farm conditions. Eggs were collected at 16:00 hours, daily and numbered.

The hen day egg production as the indicator of egg production of birds was measured using the following formula (Sing and Kumar, 1994):

Hen day production $(\%)=\frac{\text { No. of eggs laid up to } 40 \text { w eeks of age }}{\text { No. of days in lay }} \times 100$

\section{Genetic gain estimation}

Genetic gain in Fay and RIR for hen day egg production (HDEP) was estimated for each generation using the following equation (Lush, 1945):

$\mathrm{G}_{\mathrm{f}}=\mathrm{i} \times \mathrm{h}^{2} \times \sigma_{\mathrm{p}} \frac{1+(\mathrm{n}-1) \mathrm{r}}{\sqrt{\mathrm{n}\{1+(\mathrm{n}-1) \mathrm{t}\}}}$

Where, $G_{f}=$ genetic gain or responses of selection; $h^{2}=$ heritability of HDEP $\left(h^{2}\right.$ for egg production was 0.25 as per R. A. Singh, 1981); $\mathrm{n}=$ number of pullets in the family; $\mathrm{t}=$ intra class correlation of phenotypic values of members of the family; $r=$ half/ full-sib relationship among individuals; $\sigma_{p}=$ phenotypic standard deviation in HDEP 
The genetic gain found in $F_{1}, F_{2}$ and $F_{3}$ generations were regressed to find out rate of progress in selection programme. The selection differential, selection intensity and phenotypic standard deviation for hen day egg production used in the estimation of genetic gain are given in Table 1. The values of selection intensity were taken from Lush (1945) against per cent of pullets selected for the next generation.

Table 1. Data structure for estimation of genetic gain

\begin{tabular}{lcccccc}
\hline \multicolumn{1}{c}{ Generation } & \multicolumn{3}{c}{ Fayoumi } & \multicolumn{3}{c}{ RIR } \\
\cline { 2 - 7 } & $\begin{array}{c}\text { SD } \\
(\% \mathbf{H D E P})\end{array}$ & $\mathbf{i}$ & $\begin{array}{c}\mathbf{6}_{\mathbf{p}} \\
(\boldsymbol{\%} \mathbf{H D E P})\end{array}$ & $\begin{array}{c}\text { SD } \\
(\boldsymbol{\%} \mathbf{H D E P})\end{array}$ & $\mathbf{i}$ & $\begin{array}{c}\mathbf{6}_{\mathbf{p}} \\
(\boldsymbol{\%} \mathbf{H D E P})\end{array}$ \\
\hline Foundation stock & 1.08 & 0.5705 & 2.376 & 1.30 & 0.5411 & 2.419951 \\
$\mathrm{~F}_{1}$ generation & 1.88 & 0.5705 & 4.326 & 2.25 & 0.5411 & 5.366001 \\
$\mathrm{~F}_{2}$ generation & 1.50 & 0.5705 & 4.066 & 2.96 & 0.5411 & 6.099857 \\
$\mathrm{~F}_{3}$ generation & 1.69 & 0.5705 & 4.003 & - & - & - \\
\hline
\end{tabular}

SD, Selection differential; I, selection intensity; $\sigma_{\mathrm{p}}$, Phenotypic standard deviation; HDEP, Hen day egg production

\section{Data analysis}

All data were analyzed in a Completely Randomized Design (CRD) with ANOVA (Steel and Torrie, 1980) for comparing hen day egg production, fertility, hatchability and livability of Fay and RIR breed among different generations (Foundation stock, $\mathrm{F}_{1}, \mathrm{~F}_{2}$, and $\mathrm{F}_{3}$ ). Data were entered in a spreadsheet (Excel 2000, Microsoft Corporation), transferred to STAT-7 (STAT Corporation) and analyzed using SPSS computer package.

Table 2. Mean $( \pm$ SE) of egg production, fertility, hatchability and livability of Fay and RIR under farm condition: Foundation stock $\left(F_{0}\right) F_{1}, F_{2}$ and $F_{3}$ generation

\begin{tabular}{|c|c|c|c|c|}
\hline \multicolumn{5}{|l|}{ Fay } \\
\hline Parameter & $\mathbf{F}_{\mathbf{0}}$ & $\mathbf{F}_{1}$ & $\mathbf{F}_{2}$ & $\mathbf{F}_{3}$ \\
\hline Hen day egg production $(\%)^{*}$ & $64.39^{\mathrm{a}} \pm 0.38$ & $58.60^{b} \pm 0.68$ & $64.09^{\mathrm{a}} \pm 0.99$ & $65.82^{\mathrm{a}} \pm 0.71$ \\
\hline Fertility $(\%)^{*}$ & $94.00^{\mathrm{a}} \pm 0.80$ & $89.91^{\mathrm{b}} \pm 1.28$ & $94.65^{\mathrm{a}} \pm 1.22$ & $92.91^{\mathrm{a}} \pm 0.60$ \\
\hline Hatchability on total egg $(\%)^{*}$ & $73.48^{\mathrm{a}} \pm 1.50$ & $73.70^{\mathrm{a}} \pm 1.31$ & $82.96^{\mathrm{b}} \pm 1.66$ & $79.30^{\mathrm{b}} \pm 0.98$ \\
\hline Livability during laying period $(\%)^{*}$ & $91.6^{\mathrm{b}} \pm 1.18$ & $87.63^{\mathrm{a}} \pm 1.65$ & $93.80^{\mathrm{b}} \pm 1.10$ & $87.51^{\mathrm{a}} \pm 2.54$ \\
\hline \multicolumn{5}{|l|}{ RIR } \\
\hline Hen day egg production $(\%)^{*}$ & $68.54^{\mathrm{a}} \pm 0.40$ & $46.80^{b} \pm 0.89$ & $62.05^{\mathrm{c}} \pm 1.02$ & - \\
\hline Fertility $(\%)^{*}$ & $84.42^{\mathrm{a}} \pm 1.75$ & $74.39^{\mathrm{b}} \pm 1.37$ & $81.75^{\mathrm{a}} \pm 1.92$ & - \\
\hline Hatchability on total egg $(\%)^{*}$ & $63.25^{\mathrm{a}} \pm 1.49$ & $53.40^{\mathrm{b}} \pm 0.52$ & $62.61^{\mathrm{a}} \pm 1.91$ & - \\
\hline Livability during laying period $(\%)^{*}$ & $81.94^{\mathrm{a}} \pm 0.78$ & $79.53^{\mathrm{a}} \pm 1.66$ & $90.52^{b} \pm 1.37$ & - \\
\hline
\end{tabular}

${ }^{a b c}$ values with different superscripts in a row indicate significant difference; ${ }^{*}$ Significant at $\mathrm{P}<0.05$

\section{Results and Discussion}

Table 2 shows the average egg production, fertility, hatchability and livability of Fay (up to $\mathrm{F}_{3}$ generation) and RIR (up to $\mathrm{F}_{2}$ generation). It was observed that hen day egg production and fertility was higher ( $\mathrm{P}<$ 
$0.01)$ in Foundation stock than that of $F_{1}$ generation but no significant difference $(P>0.05)$ was observed for livability and hatchability between Foundation stock and $\mathrm{F}_{1}$ generation. Reasons for lower productivity in $F_{1}$ generation of Fay and RIR may be for poor management practices and the inability to adjust in tropical climate (in case of RIR).

In $\mathrm{F}_{2}$ generation, egg production was higher in both the breeds (64.09\% in Fay and $62.05 \%$ in RIR) than in $F_{1}$ generation. Egg production data of RIR was not recorded for $F_{3}$ generation, perhaps the performance occurred for RIR to thrive under semi intensive system was very poor. However, in $\mathrm{F}_{3}$ generation, egg production of Fay was higher $(65.82 \%)$ than in $\mathrm{F}_{2}$ generation.

Table 3. Genetic gain in selection programme of Fayoumi and RIR population

\begin{tabular}{lcc}
\hline Generation & \multicolumn{2}{c}{ Genetic gain (\% HDEP/generation) } \\
\cline { 2 - 3 } & Fayoumi & RIR \\
\hline $\mathrm{F}_{1}$ generation & 0.06 & 0.07 \\
$\mathrm{~F}_{2}$ generation & 0.11 & 0.18 \\
$\mathrm{~F}_{3}$ generation & 0.12 & - \\
\hline
\end{tabular}

The genetic merits of Fay and RIR laying hens for hen day egg production (HDEP) were 0.06 and 0.07 in $F_{1}, 0.11$ and 0.18 in $F_{2}$ and 0.12 in $F_{3}$ generations, respectively (Table 3). The declined \% HDEP of Fay and RIR in $\mathrm{F}_{1}$ generation besides their positive genetic merits for the trait may be for poorer adaptation under intensive system. Phenotypic performances of poultry may be lower than that of their genetic potential without support of proper environment and management care (Lasley, 1987).

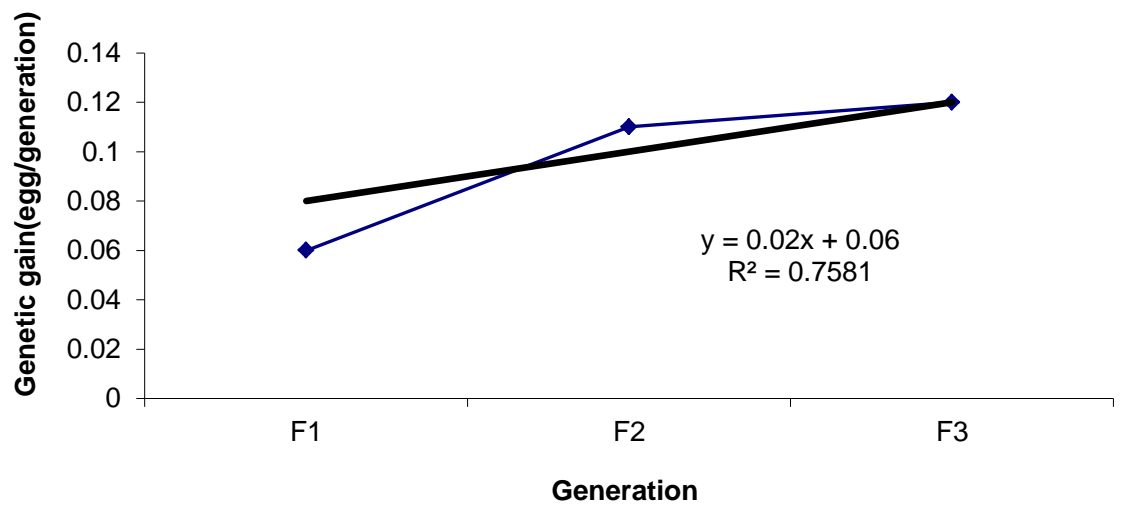

Fig 1: Genetic gain in percent HDEP of Fayoumi laying hens

The Figure 1 and 2 shows that per cent hen day egg production of Fay and RIR breed were increased over the generation. However, the rate of genetic gain was very low to get rapid improvement in laying performances of the breeds. The rate of genetic gain was $0.02 \mathrm{egg} /$ generation in Fay and $0.044 \mathrm{egg} /$ generation in RIR. This genetic gain does not correlate with phenotypic performances of Fay and RIR. However, in some circumstances genetic gain in production traits might be hindered by environmental 
influences (Pidduck, 1995). It is mentioned that lower productivity was found during experimental period as managemental practices (water, electricity etc.) were interrupted for shorter period.

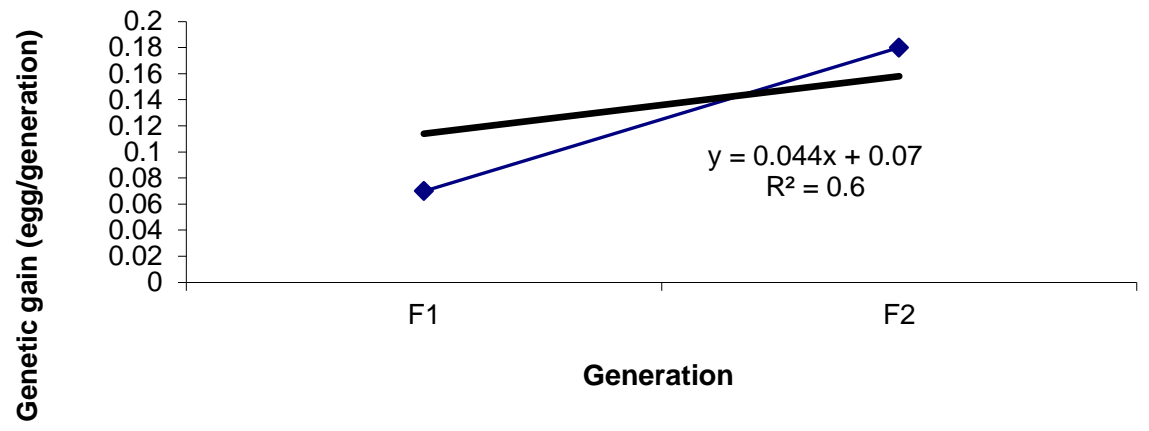

Fig 2: Genetic gain in percent HDEP of RIR laying hens

\section{Conclusion}

Hen day egg production of Fay and RIR was found to response suitably to selection with higher rate of lay. The rate of genetic gains so far achieved in the breeding stocks from selective breeding within a small population is required to be increased by many folds to get commercially viable high producing Fay and RIR hens. Selection with larger flock might give a better understanding of selection response.

Selection of Fay may be continued with improved bio-security system for several generations with a larger flock to provide continuous supply of Fay to support the rural poultry production.

\section{Acknowledgements}

The Danish International Development Agency (DANIDA) is acknowledged with many thanks for funding this research through Smallholder Livestock Development Project (SLDP) -2 of the Department of Livestock Services (DLS). Thanks are due to Mr. Md. Golam Mostafa, Project Director, SLDP- 2 for allowing to implement the research project.

\section{References}

Ahmed, S. and Islam, M.N. 1985. Backyard poultry Development project in 100 villages. Sponsored by Bangladesh Agricultural University and assisted by UNICEF, Bangladesh. Proceedings of the $1^{\text {st }}$ conference of the Bangladesh Animal Husbandry Association, February 23-24, BARC, Dhaka.

Ali, I. 1989. Reproductive performances of Fayoumi, Rhode Island Red and Fayoumi $\times$ Rhode Island Red crossbred hens and subsequent growth rate of their offspring up to sexual maturity. M. Sc. Thesis. Department of Poultry Science, Bangladesh Agricultural University, Mymensingh.

Anisuzzaman, M. 1988. A study on growth rate, feed efficiency and livability of Fayoumi chicken under Bangladesh condition. M. Sc. Thesis. Department of Poultry Science, Bangladesh Agricultural University, Mymensingh. 
Barua, A., Howlider, M.A.R. and Yoshimura, Y. 1998. A study on the performance performance of Fayoumi, Rhode Island Red and Fayoumi $\times$ Rhode Island Red chickens under rural condition of Bangladesh. Asian Australasian Journal of Animal Science. Vol. 11(6): 635-641.

Barua, A. and Howlider, M.A.R. 1990. Prospect of native chicken in Bangladesh. Poultry Adviser, 23: 5761.

Bulbul, S.M. 1983. More protein for the undernourished through a village poultry project. Maximum livestock production from minimum land, C. H. Davis; C. R. Preston; M. Hoque and M. Saadullah, 1983. Proceedings oh the 4th seminar held at BAU, Mymensingh.

Haque, M.E. 2003. The effects of incorporating local naked neck gene in exotic high yielding chicken to synthesis types suitable for rural poultry production. Ph. D. Thesis, Dept of Poultry Science, Bangladesh Agricultural University, Mymensingh.

Horst, P. and Mathur, P.K. 1989. Position of local fowl for tropically oriented breeding activities. Genotype $x$ environment interactions in poultry production. JOUY-EN-jOSAS (fRANCE), mA 911, 1989. PP. 159-174.

Huque, Q.M.E., Ebadul, M.H. and Rigor, E.M. 1990. The effect of chick separation on productivity of the hen and chick. Asian- Australasian Journal of Animal Science. 3(2): 121-123.

Huque, Q.M.E. 1993. Indigenous animal species: Conservation verses intensive production in Bangladesh. Livestock Production. XVIII (10): 132-137.

Huque, Q.M. E., Choudhury, S. A., Haque, M. E. and Sil, B. K. 1999. Poultry research in Bangladesh: Present status and its implication for future research. In: F. Dolberg, and P. H. Peterson, Eds. Proceedings of a workshop on "Poultry as a Tool in Poverty Eradication and Promotion of Gender Equality”. Pp:151-164

Islam, A.B.M., Hoque, M.M. and Rahim, Q.M.F. 1981. Reproductive performance of upgraded indigenous chicken. Poultry Adviser. 14: 33-37

Khan, A.G. 1983. Indigenous germplasm, Poultry Guide (India). 8: 59-64.

Lasley, J.F. 1987. Genetics of Livestock Improvement. 4th edition. Prentice-Hall, Inc, Englewood Cliffs, New Jersey.

Lush, J.L. 1945. The family structure of populations. In: Animal Breeding Plans. 3rd edition. Iowa State College press. Pp: 308-327.

Miah, M.S., Islam, M.A. and Ali, M.A. 2002. Growth and egg production performance of exotic pure breed and crossbreeds chicken. The Bangladesh Veterinarian, 19 (1): 43-47.

Okada, I., Maeda, Y., Ota, K., Namikwa, T., Amano, T. and Kurosawa, Y. 1989. Genetical studies on breed difference of the native chicken in Bangladesh, In: Genetic studies on breed difference of the native domestic animals in Bangladesh, part 2, Hiroshima University. Pp. 11-26.

Panda, B. 1989. Structure and problems of poultry industry in Southern Asia, World's Poultry Science Journal. 45: 66-71. 
Pidduck, H.G. 1995. Genetic consideration in Animal Breeding. In: Animal Breeding andInfertility. Edited by M. J. Meredith. Blackwell Science Ltd. USA pp: 1-38

Rahman, M., Sorensen, P., Jensen, H.A. and Dolberg, F. 1997. Exotic hens under semi scavenging conditions in Bangladesh. Livestock research for Rural Development. 9 (3): 1-11

Rao, C.V. 1990. Native fowl genetic resources in India- A study perspective. Poultry Guide. 27 (6): 3439.

Sazzad, M.H. 1986. Reproductive performance of desi hens under scavenging and intensive system of rearing. Proceedings of the 1st Annual livestock Research Workshop. Bangladesh Livestock Research Institute, Savar, Dhaka

Singh, R.P. and Kumar, J. 1994. Biometrical methods in Poultry Breeding, Kalyani Publishers, New Delhi.

Steel, R.G.D. and Torrie, J.H. 1980. Principles and procedures of Statistics, Mcgrow-Hill Book Company Inc., USA. 